\section{Magnetically Coupled Adjustable Speed Motor Drives}

Alternating current electric motors rotate at a nearly constant speed that is determined by motor design and line frequency. Energy savings of 50\% or more may be available when fixed speed systems are modified to allow for variable load requirements of a centrifugal fan or pump.

Loads that vary by $30 \%$ of full load over time offer good opportunities for cost-effective adjustable speed drive (ASD) retrofits. Market assessment studies indicate that in light and medium industries, $26 \%$ of motors exhibit fluctuating loads; $22 \%$ of these are in process industries and 35\% are in other heavy industries. However, industrial ASD installations remain relatively low. The majority of ASD-equipped industrial motor systems are 20 horsepower (hp) or less - and often the ASD is installed to improve control over the production process versus energy savings. ${ }^{2}$ Thus potential energy and costs savings from ASD installations are significant.

\section{Variable Frequency Drives}

The electronic pulse-width-modulated variable frequency drive (VFD) is the most common type of ASD and is the state-of-the-art speed control. Because of energy efficiency and control capabilities, VFD and motor combinations have replaced constant speed motors in virtually every type of industrial plant. Although VFDs have been available for many years, they are not suited for all applications. Many industrial plants use medium voltage ( $>600$ to 6,600 volts [V]) to supply power to motors rated as low as $150 \mathrm{hp}$. Semiconductors for medium voltage motor applications are particularly expensive. Depending on the situation, other factors that can discourage the use of VFDs include:

- Creation of harmonics, which requires installation of line reactors or harmonic filters

- Voltage spikes that can lead to early motor failure

- Motor bearing failures caused by induced shaft currents that flow to ground through the bearing's rolling elements

- Nuisance tripping

- Limitations on the distance between the motor and VFD.

\section{Magnetically Coupled ASDs}

In contrast to a VFD, a magnetically coupled ASD does not alter the power supplied to the motor. With a magnetically coupled ASD, the motor is generally brought up to operating speed while unloaded. The motor continues to operate at the rated design speed while the magnetic coupling controls the torque transferred and the speed of the driven equipment. This works by varying the strength of the magnetic field between the motor shaft and the load shaft. The strength of the magnetic field is controlled by varying the width of an adjustable air gap or by varying the amount of current applied to an electromagnet.

Because the load and motor shafts are not directly coupled, vibrations that occur on the load side are isolated and not transmitted to the motor. For instance, a newsprint products plant installed a magnetically coupled ASD for a 250-hp/2,300-V motor running a centrifugal pump with a bypass flow control valve. This resulted in annual energy savings of 633,000 kilowatt-hours. Long-term maintenance costs decreased as pump cavitation was eliminated and vibration was dramatically reduced. ${ }^{3}$

\section{Suggested Actions}

- Complete a survey to identify constant speed motors in your plant that drive centrifugal pumps with throttling valves or recirculation (bypass) lines or centrifugal fans equipped with inlet guide vanes and/or discharge dampers.

- Determine the load profile for systems that are in use more than 2,000 hours per year.

- Determine the energy savings and cost effectiveness of installing a VFD or magnetically coupled ASD motor controller.

- Consider magnetically coupled ASDs for medium-voltage motors, when sensitive equipment cannot tolerate harmonic currents or maintenance requirements are high because load vibrations are transferred to motor bearings. 
Magnetically coupled ASDs do not have to be housed in a controlled environment. They allow for multiple motor starts with no "cool-off period" and are desirable when harmonic distortion cannot be tolerated or if poor power quality would cause excessive nuisance trips. This design also inherently provides load seizure protection. Because magnetically coupled ASDs operate independently of motor power supply voltage, they are often cost effective in applications with medium-voltage power supplies. These ASDs have other advantages, including compatibility with existing standard efficiency motors, avoidance of additional motor heating and the need for motor de-rating, and accommodation of shaft thermal expansion.

Disadvantages of magnetically coupled ASDs include space and weight constraints. Some are not compatible with vertical-shaft motors or belt-driven loads. They are also maintenance intensive and require repair by technicians with specialized training.

Magnetically coupled ASDs offer some operating advantages that are desirable for niche applications. They provide speed control that can be up to $30 \%$ more efficient than fan damper control and $44 \%$ more efficient than using throttling valves for pump flow control. However, they capture only about $60 \%$ of potential energy savings compared to conventional VFDs. Relative to a conventional ASD, energy savings decrease as the motor operating speed is reduced. ${ }^{4}$

\section{References}

${ }^{1}$ ADM Associates, Inc., Adjustable-Speed Drive Case Studies, prepared for the Wisconsin Center for Demand-Side Management, 1994.

${ }^{2}$ Xenergy, Inc., United States Industrial Motor Systems Market Opportunities Assessment, prepared for the U.S. Department of Energy's Office of Industrial Technologies, December 1998.

${ }^{3}$ Northwest Energy Efficiency Alliance, Field Testing the MagnaDrive Coupling Speed Control Technology on Northwest Industrial Applications, "Case Study: Ponderay Newsprint, Usk, Washington," 2000.

${ }^{4}$ Motor Systems Resource Facility, Oregon State University, Product Testing: MagnaDrive, Report No. 1, prepared for the Northwest Energy Efficiency Alliance, March 2000.

\section{Additional References}

Dan Greenberg, Platts Research and Consulting, Magnetically Coupled Adjustable-Speed Drives: Going Where No VFD Has Gone Before, ER-03-18, November 2003.

Quantec, Market Progress Evaluation Report: MagnaDrive, No. 2, prepared for the Northwest Energy Efficiency Alliance, Report E02-099, May 2002.

\section{Resources}

National Electrical Manufacturers Association (NEMA) -Visit wwW. nema.org for information on motor standards, application guides, and technical papers.

U.S. Department of Energy (DOE)-
For more information on motor
and motor-driven system
efficiency and to download the
MotorMaster+ software tool, visit
the Advanced Manufacturing
Office (AMO) website at
manufacturing.energy.gov.

U.S. Department of Energy (DOE)For more information on motor and motor-driven system efficiency and to download the MotorMaster+ software tool, visit the Advanced Manufacturing manufacturing.energy.gov.

\section{Energy Efficiency \&} Renewable Energy
Manufacturing converts a wide range of raw materials, components, and parts into finished goods that meet market expectations. The Advanced Manufacturing Office (AMO) partners with industry, small business, universities, and other stakeholders to identify and invest in emerging technologies with the potential to create high-quality domestic manufacturing jobs and enhance the global competitiveness of the United States.
Advanced Manufacturing Office Energy Efficiency and Renewable Energy U.S. Department of Energy Washington, DC 20585-0121 manufacturing.energy.gov

DOE/GO-102012-3738 • November 2012 